\title{
Cruise VII. of the Carnegie, I928-I93I.
}

By Dr. J. A. Fleming and Capt. J. P. Aulr, Department of Terrestrial Magnetism, Carnegie Institution of Washington.

$A$ FTER an interval of more than six years, the A Carnegie began again on May 1, 1928, a world-wide cruise planned to continue to September 1931. This will be the seventh cruise of the vessel and, as indicated by the tentative route shown in Fig. 1, will add 110,000 statute miles to the total of nearly 290,000 miles traversed in all oceans during Cruises I. to VI. (1909-1921). Thus the plans for the magnetic and electric survey of the oceans envisioned in 1904, under the enthusiastic and energetic directorship of Dr. Louis A. Bauer, netic work already done on the Carnegie is attested by the principal hydrographic establishments of the world and by individual investigators. While magnetic data are needed for practical navigators, yet future magnetic work at sea is far more necessary for the advancement of theoretical studies. Accumulated data indicate that the accelerations in the secular variation changes may not be extrapolated safely over periods so long as five years. Observations will be repeated in localities previously surveyed by the Galilee and the Carnegie,

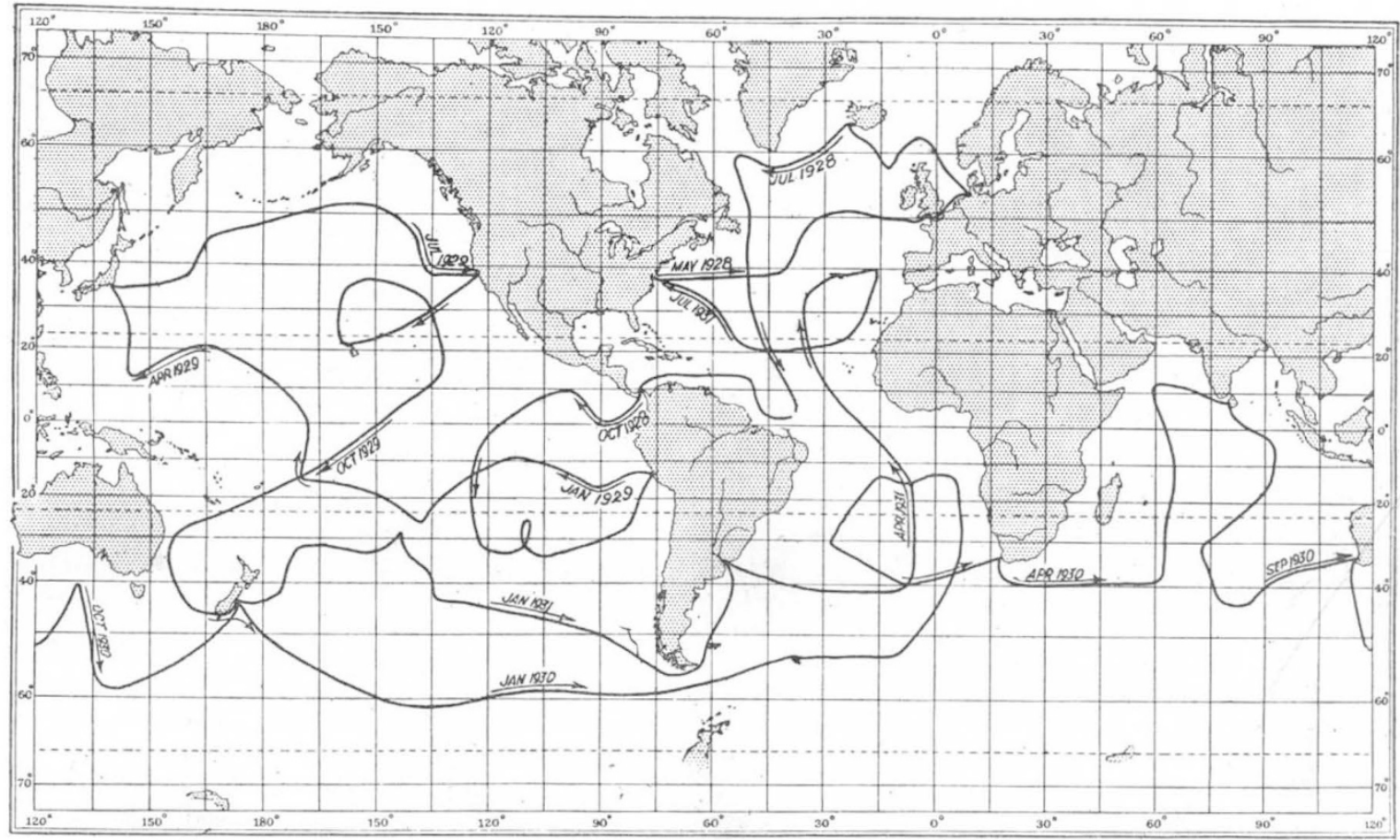

Fig. 1.-Tentative route for Cruise VII. of the Carnegie, 1928-1931.

will be further realised and the results already obtained will be greatly enhanced.

The survey of the oceans of the world was begun during 1905-8 on the chartered brigantine Galilee in the then magnetically unexplored Pacific under the command, respectively, of J. P. Pratt for the first cruise, and W. J. Peters for the second and third cruises. Upon completion of the specially designed yacht Carnegie in 1909, the survey was continued with greater efficiency, because of non-magnetic construction of the vessel and the steady evolution of suitable instruments and observational methods, in all oceans during 1909-21 under the command, respectively, of W. J. Peters for Cruises I. and II., of Capt. J. P. Ault for Cruises III., IV., and VI., and of H. M. W. Edmonds for Cruise V.

The practical and theoretical value of the mag- and additional information will be obtained regarding the distribution of the magnetic elements in some large areas not already covered.

Experience during previous cruises has shown that results with certain magnetic methods and instruments are more trustworthy than with others, so that the duplication of instruments and methods need not be continued. Thus the magnetic declination will be determined by use of the marine collimating-compass, omitting the deflector; the horizontal intensity will be determined by the deflector, omitting the dip circle method ; the magnetic inclination will be determined with the earth inductor, omitting the dip circle. Some improvements have been made in the magnetic instruments, chief among which is the addition of a constant speed apparatus and drive for rotating the coil of the earth'inductor, with amplifier and micro-

No. 3057, VoL. 121] 
ammeter to determine inclination electromagnetically. Electromagnetic methods are also to be attempted with the earth inductor for the measurement of the horizontal intensity, thus replacing the more laborious deflector method by a more rapid and accurate electric method.

For the further investigations on the origin and maintenance of the earth's electric charge and of their relation to the earth's magnetic condition, determinations of changes in the values of the atmospheric electric elements with geographic position are needed in addition to those already made. A photographic recorder will be used to record variations in atmospheric potential gradient continuously ; it will be mounted near the top of the mainmast and will be controlled by the appar-

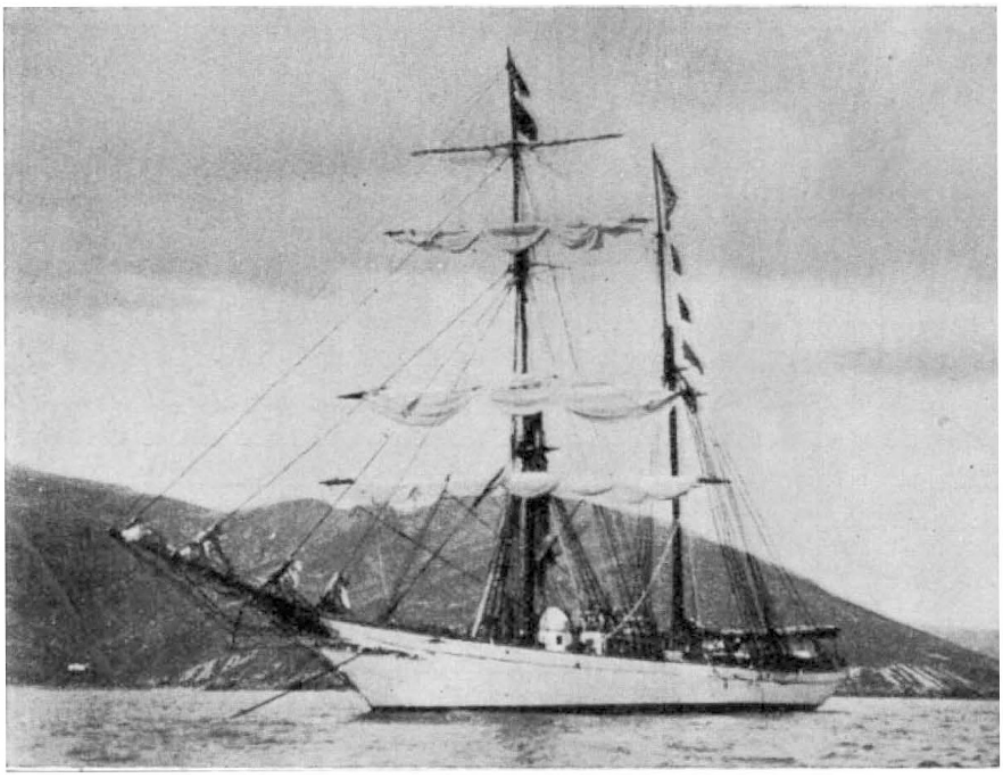

FIG. 2.-Non-magnetic yacht Carnegie off Port Lyttelton, New Zealand. During six cruises in all oceans (1909-21), the vessel has sailed about 290,000 miles. vessel. marine electric currents will be attempted by trailing electrodes on cables from the stern of the

The important contributions to the study of various geophysical problems, which are being made by investigations of the Heaviside conducting layer and of radio transmission and variations with changing magnetic and electric conditions, greatly enhance the value of the atmospheric electric data already collected on the Carnegie over the ocean areas, and indicate co-operative investigations along similar lines for the coming cruise.

The omission of duplicate magnetic methods and instruments previously mentioned, and addition of two men to the scientific personnel, make possible a substantial programme in physical and biological oceanography. In physical oceanography it is planned to investigate the topography and configuration of the ocean depths by the sonic depth-finder; to study the causes of movements of vast bodies of water relatively to one another, the dynamics of the sea, by measuring differences in temperature and salinity over the surface and at various levels down to a maximum of 20,000 feet; to secure information regarding the nature and derivation of inorganic marine deposits by sampling the bottom muds and sediments; and to increase our knowledge of the physical interchange between the surface of the ocean and the air above it by measuring the temperature and humidity lapse-rates of the air in the first 100 feet above the surface, and by observing the variations in the amount of solar radiation received at the ocean surface.

Work in marine biology will atus for eye-readings mounted on the quarter-deck railing as heretofore. A motor has replaced the spring and clock-work mechanism in the ioniccontent apparatus for drawing the air through the instrument.

Some improvements have been made in the instruments and methods used for measuring the penetrating radiation and the radioactive content, and more frequent series of observations extending over a period of twenty-four hours are planned. In addition to the programme previously followed for observations of the penetrating radiation, parallel observations will be made with a Kolhörster instrument which Dr. Kolhörster is testing thoroughly and comparing with his 'standard' instrument. It is planned to observe especially for variations with time, with geographical position, and with depth. Dust-count observations, using an Aitken dustcounter, will be made for correlative studies with atmospheric electricity. The measurement of be confined to microbiology, to determine the abundance and distribution of plankton and other small organisms. Most of the collecting will be done by tow-nets and dip-nets. A special boom-walk, similar to the one used by Beebe, has been installed on the starboard forward side of the vessel, where the collector may walk 30 feet out from the side of the ship on a plank suspended by a netting of rope from two boatbooms and about three feet below them. The booms are hinged at the rail and are suspended from the mast by a pendant with preventer stays both forward and aft. Shallow-water dredging will be undertaken to secure diatoms and foraminifera, and specimens of porpoises, dolphins, birds, and other creatures will be collected from special regions.

To carry out this programme of oceanographic investigations and to provide for new equipment required many changes in the Carnegie. The

No. 3057, VoL. 121] 
structural changes were made during the summer of 1927, when the vessel was completely overhauled and reconditioned at Hoboken, New Jersey. The two lifeboats were removed from the quarter-deck to overhead platforms amidships, thus leaving the quarter-deck free for the operation of the winch, sounding wire, water-bottles, deep-sea reversing thermometers, tow-nets, bottom-samplers, and earth-current cables. Two new laboratories were constructed on the main-deck, one designed for oceanographic investigations, and one for radio and sound work. In the oceanographic laboratory are mounted the Wenner electric salinity apparatus, the Negretti and Zambra distant-recording surface temperature thermograph operating on a 24-hour rate, and the various equipment and apparatus for the study of planktion and of the chemistry of the air and of sea water.

In the radio and sound laboratory is mounted the depth-finder loaned by the United States Navy Department for measuring rapidly and accurately the depths of the sea. The short-wave transmitting and receiving radio equipment made after the design of the United States Naval Research Laboratory, for the investigation of variations in transmitting and receiving conditions and on skip distances and signal intensity, is installed in this laboratory.

In a new galvanometer house on the port side of the quarter-deck aft of the radio laboratory, are mounted the Einthoven type string galvanometer for the earth inductor and for the earth-current apparatus, the control portion of the constant speed apparatus, amplifying unit, microammeter, special inductance coils, and appurtenances for the earth inductor work, the recording apparatus for six resistance thermometers located at various places from the masthead to near the ocean surface, and the roll-and-pitch recorder.

The oceanographic equipment includes a Wenner electrical salinity apparatus made in the Department's shop, Richter and Wiese thermometers and water-bottles, Nansen water-bottles, special nonmagnetic winch with 6800 -foot and 20,000 -foot aluminum-bronze cables for depth-work, sonic depth-finder loaned by the United States Navy Department, chemical and biological apparatus, silk metre and half-metre plankton nets, various types of bottom - samplers, and necessary appurtenances.

The meteorological instruments are in general of the recording type, and a special programme of observation and control has been arranged. At Plymouth and at Hamburg, additional recording wet- and dry-bulb thermograph and wetand dry-bulb resistance thermometer equipment with recording galvanometer for three stations at masthead, cross-tree, and meteorological screen are to be installed. It is hoped that, despite the difficulties of such work on a sailing vessel, data on the general upper-air circulation may be obtained by pilot-balloon flights, for which equipment is provided.

The members of the scientific personnel and their special fields of activity are : Capt. J. P. Ault, commander and chief of scientific staff; Wilfred C. Parkinson, senior scientific officer, atmospheric electricity and photography; Oscar W. Torreson, navigator and executive officer, magnetism, navigation, and meteorology ; F. M. Soule, observer and electrical expert, magnetism and physical oceanography; H. R. Seiwell, chemist and biologist, oceanography; J. H. Paul, surgeon and observer, medical work, meteorology, and oceanography; W. E. Scott, observer, navigation and commissary; Lawrence A. Jones, radio operator and observer, radio investigation and communication. The sailing staff will consist of 17 men, making the total number of men on board 25 ; of the sailing staff, A. Erickson, first watch-officer, C. E. Leyer, engineer, and F. Lyngdorf, steward, occupied similar positions during the entire two years of the Carnegie's last cruise.

The first leg of the cruise will be to Plymouth, England, where the vessel was due to arrive at the end of May. After a call at Hamburg, the next ports of call will be at Iceland, at Barbados, and at the Panama Canal Zone (about the end of October 1928). The remainder of the cruise (see Fig. 1) will cover the North Pacific, South Pacific, South Atlantic, Indian, and North Atlantic oceans. Among the ports of call will be Easter Island, Callao, Papeete, Apia, Guam, Yokohama, San Francisco, Honolulu, Lyttelton, South Georgia, St. Helena, Cape Town, Colombo, St. Paul, Fremantle, Rapa Island, Buenos Aires, Ponta Delgada, and Madeira.

The preparations for this cruise have had generous co-operation and expert advice on all sides from interested governmental and private organisations and individuals both in America and Europe, who have also either loaned or presented much of the special oceanographic equipment and many books for the reference library on board. Among these the Carnegie Institution of Washington is indebted to the following: United States Navy Department, including particularly its Hydrographic Office, Naval Research Laboratory, Signal Corps and Air Corps of the War Department, Coast Guard, National Museum, Bureau of Fisheries, Weather Bureau, and Coast and Geodetic Survey; Scripps Institution of Oceanography of the University of California ; Museum of Comparative Zoology of Harvard University; School of Geography of Clark University ; American Radio Relay League; Geophysical Institute, Bergen, Norway; Marine Biological Association of the United Kingdom, Plymouth, England; German Atlantic Expedition of the Meteor; Institut für Meereskunde, Berlin, Germany ; British Admiralty, London ; Carlsberg Laboratorium, Bureau International pour l'Exploration de la Mer, and Laboratoire Hydrographique, Copenhagen, Denmark; and many others. Dr. H. U. Sverdrup, of the Geophysical Institute at Bergen, Norway, research associate of the Carnegie Institution of Washington, is consulting oceanographer and physicist. 